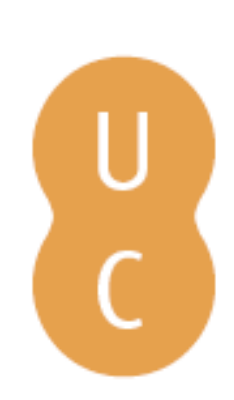

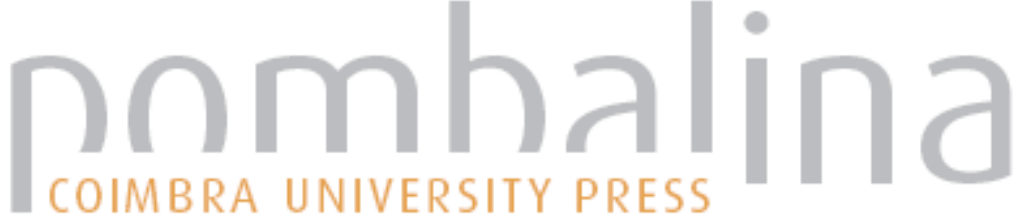

\section{O de pictura e a mensurabilidade das edificações pintadas}
Autor(es):
Brock, Maurice
Publicado por: Imprensa da Universidade de Coimbra
URL persistente:
URI:http://hdl.handle.net/10316.2/36672
DOI:
DOI:http://dx.doi.org/10.14195/978-989-26-1015-3_10
Accessed : $\quad$ 26-Apr-2023 12:24:01

A navegação consulta e descarregamento dos títulos inseridos nas Bibliotecas Digitais UC Digitalis, UC Pombalina e UC Impactum, pressupõem a aceitação plena e sem reservas dos Termos e Condições de Uso destas Bibliotecas Digitais, disponíveis em https://digitalis.uc.pt/pt-pt/termos.

Conforme exposto nos referidos Termos e Condições de Uso, o descarregamento de títulos de acesso restrito requer uma licença válida de autorização devendo o utilizador aceder ao(s) documento(s) a partir de um endereço de IP da instituição detentora da supramencionada licença.

Ao utilizador é apenas permitido o descarregamento para uso pessoal, pelo que o emprego do(s) título(s) descarregado(s) para outro fim, designadamente comercial, carece de autorização do respetivo autor ou editor da obra.

Na medida em que todas as obras da UC Digitalis se encontram protegidas pelo Código do Direito de Autor e Direitos Conexos e demais legislação aplicável, toda a cópia, parcial ou total, deste documento, nos casos em que é legalmente admitida, deverá conter ou fazer-se acompanhar por este aviso.

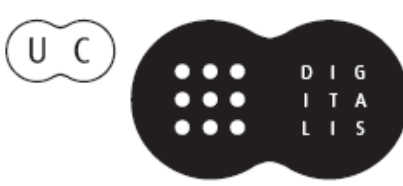


IMPRENSA DA

UNIVERSIDADE

DE COIMBRA

COIMBRA

UNIVERSITY

PRESS

\section{NA GÉNESE DAS RACIONALIDADES MODERNAS II}

Em torno de Alberti e do Humanismo

MÁRIO KRÜGER et alii

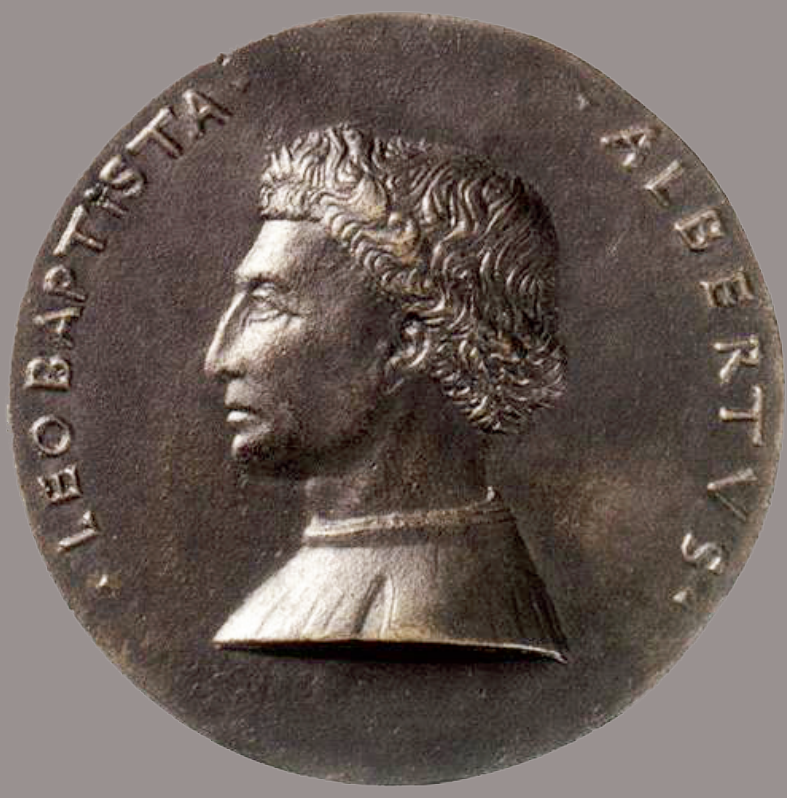




\section{O DE PICTURA E A MENSURABILIDADE DAS E D I F I C A Ç Õ ES P I N T A D A S}

Maurice Brock

\section{Resumo}

No De pictura, Alberti contrapõe as dimensões visíveis do pavimento e das edificações àquelas dos personagens. Ele considera, com efeito, que os paralelepípedos do pavimento devem ter laterais medindo um "braço", ou seja, o equivalente a um terço da altura total do homem. Segue-se que a largura e a profundidade das edificações implantadas no pavimento são determinadas a partir deste último: elas devem ser avaliadas em número de "braços". Por outro lado, a altura dos edifícios deve, segundo Alberti, ser determinada em relação à altura total do homem: seja equivalente a esta altura, seja um múltiplo inteiro. O presente artigo sugere, na base de dois estudos de caso, que os preceitos do teórico não se encontram refletidos nas práticas dos artistas. Constata-se de fato que, nas obras, as dimensões dos paralelepípedos do pavimento são geralmente determinadas a partir dos pés dos personagens (ao passo que Alberti refuta a utilização do pé como unidade de medida). Observa-se igualmente que a altura das edificações é raramente um múltiplo inteiro da altura total do homem. De Pictura; Dimensions; Contradition Theorie-Pratique

\section{Résumé}

Dans le De pictura, Alberti rapporte les dimensions apparentes du dallage et des édifices à celles des personnages. Il estime en 
effet que les carreaux du dallage doivent avoir des côtés mesurant un "bras", c'est-à-dire équivalant à un tiers de la hauteur totale de l'homme. Il en résulte que la largeur et la profondeur des édifices implantés sur le dallage sont à déterminer à partir du dallage: elles doivent être évaluées en nombre de "bras". En revanche, la hauteur des édifices doit, selon Alberti, être déterminée par rapport à la hauteur totale de l'homme: soit elle équivaut à cette hauteur, soit elle en est un multiple entier. La présente contribution suggère, sur la base de deux études de cas, que les préconisations du théoricien ne recoupent pas la pratique des artistes. On constate en effet que, dans les ouvres, les dimensions des carreaux du dallage sont le plus souvent déterminées à partir des pieds des personnages (alors même qu'Alberti refuse d'employer le pied comme unité de mesure). On constate également que la hauteur des édifices est rarement un multiple entier de la hauteur totale de l'homme.

De Pictura; Dimensions; Contradition Theorie-Pratique

Alberti's De pictura opposes the visible floor and buildings' dimensions with those related with people's representation. He believes, indeed, that floor paving stones must have one 'arm' lateral dimension, i.e., equivalent to one-third of the total height of a man. It follows that the width and depth of buildings set on the pavement are determined from the latter: they must be evaluated in number of "arms". On the other hand, the height of the buildings should be, according to Alberti, defined over the full height of a man: either equal to it or to an integer multiple of it. This article suggests, based on two case studies, that theoretical precepts are not reflected in artists' practices. It appears indeed in these works that floor cobblestones dimensions are generally determined from people's feet (whereas Alberti rejects the use of foot as a unit of measurement). It is also observed that the height of buildings is rarely an integer multiple of the total height of a man.

De Pictura; Dimensions; Contradition Theorie-Pratique 
É notório o fato de Alberti ter demonstrado vivo interesse pelas medidas, sejam elas exatas ou estimadas. Sua obra escrita o comprova sobejamente. Para tomar apenas quatro exemplos, todos datados de meados do século, mencionaremos as "Tabulae dimensionum hominis" que ele traça ao final do De statua; o enunciado do problema $\mathrm{n}^{\circ} 1$ dos Ex ludis rerum mathematicarum (Se volete solo col vedere, sendo in capo d'una piazza, misurare quanto sia alta quella torre quale sia a piè della piazza [...]); os quinze "Tabulae" que rematam a Descriptio Vrbis Romae ou enfim as considerações sobre a concinnitas, ou a commensuratio, formuladas abundantemente por ele no De re aedificatoria. Mas qual é o interesse por medidas nos cerca de dez ou quinze anos anteriores, no De pictura? E quanto à produção dos pintores toscanos contemporâneos a Alberti? Nós nos concentramos primeiramente nas recomendações de Alberti sobre as medidas para a arquitetura pintada, pela simples razão da teorização do uso da perspetiva - que constitui uma das principais contribuições do De pictura - aplicar-se exclusivamente à arquitetura. Veremos em seguida, a partir de alguns exemplos, que a produção dos pintores toscanos ativos à época de Alberti não devem muito às prescrições do De pictura.

Ao tratar da questão das medidas no De pictura, Alberti começa por afirmar que apenas um procedimento comparativo oferece ao observador a possibilidade de estimar as dimensões projetadas para os objetos representados (pavimento, edificações, personagens, etc.). Ora, o termo de comparação mais adequado é, segundo ele, o corpo humano, em razão de ser conhecido de todos. Ao pintor, Alberti prescreve começar pela altura de um ser humano de estatura média, em pé, implicitamente adulto, para determinar inicialmente a localização do "ponto cêntrico" (ou seja, do ponto de fuga) e da "linha cêntrica" (isto é, da linha do horizonte), em seguida as dimensões do pavimento e enfim, as dimensões das edificações. Em outras palavras, sua abordagem se fundamenta em um princípio - a "força da comparação" - e se desdobra em quatro grandes etapas: localização do ponto de fuga; dimensões dos paralelepípedos do pavimento pintado; comprimento e largura das edificações pintadas; altura destas edificações. Abordaremos, na ordem, o princípio citado e suas etapas. 
1. Em I $§ 18$, sobre como nos tornamos conscientes dos acidentes (no sentido aristotélico) que afetam as coisas, Alberti se refere nomeadamente ao célebre adágio de Protágoras:

"Com efeito, o grande e o pequeno, o longo e o breve, o alto e o baixo, o largo e o estreito, o claro e o obscuro, o luminoso e o sombreado; e outras coisas semelhantes porque podem estar e não estar inerentes às coisas, os filósofos costumam chamá-los de acidentes e são de tal ordem que todo o seu conhecimento se processa por comparação. [...] Faz-se comparação sobretudo com as coisas mais conhecidas. E como para nós o homem é a coisa mais conhecida, talvez Protágoras, ao dizer que o homem era a dimensão e a medida das coisas, entendesse que todos os acidentes das coisas podiam ser conhecidos, comparados com os acidentes dos homens." 286

Logo em seguida, para ilustrar o que acaba de dizer, Alberti evoca um quadro - desaparecido, naturalmente - do pintor grego Timantes, no qual o tamanho dos sátiros equivalia ao polegar de um ciclope adormecido - o que o conduz a enaltecer o que chama de "força da comparação":

"O que digo tem como objetivo dar a entender que todos os corpos pequenos pintados na pintura parecerão grandes ou pequenos em comparação com o homem que aí esteja pintado. E parece-me que Timantes, melhor que todos os outros pintores antigos, soube apreciar essa força da comparação, pois ele, pintando em um quadro bem pequeno um ciclope gigante adormecido, colocou lá alguns deuses sátiros que tinham o

286 AlBerTi, L. B. Da Pintura. Tradução de Antonio da Silveira Mendonça - 2a . edição. Campinas: Editora da Unicamp, 1999, pp. 92-93. Os textos em latin são citados de LEON BATTISTA ALBERTI, De pictura, dans ID., Opere volgari, a cura di Cecil Grayson, vol. III: Trattati d'arte, Ludi rerum mathematicarum, Grammatica della lingua toscana, Opuscoli amatori, Lettere, Bari, Laterza, 1973, pp. 5-107 et ID., De pictura, Reprint a cura di Cecil Grayson, Roma-Bari, Laterza, 1975. De pict., I §18: "Nam magnum, parvum, longum, breve, altum, infimum, latum, arctum, clarum, obscurum, [luminosum], tenebrosum et huiusmodi omnia quae, cum possint rebus adesse et non adesse, ea philosophi accidentia nuncuparunt, huiusmodi sunt ut omnis earum cognitio fiat comparatione. [...] Fit quidem comparatio ad res imprimis notissimas. Sed cum sit homo rerum omnium homini notissimus, fortassis Protagoras, hominem inquiens modum et mensuram rerum omnium esse, hoc ipsum intelligebat rerum omnium accidentia hominis accidentibus recte com-parari atque cognosci.". 
tamanho de seu dedo polegar; dessa forma, comparando-se o que dormia com os sátiros, o ciclope parecia enorme."287

Veremos que, como Alberti, os pintores recorrem sistematicamente à "força da comparação", mas que o fazem, em sua grande maioria, segundo modalidades um pouco diversas. Por exemplo, confrontam frequentemente adultos e crianças (ou seres humanos e animais).

2. Em I §19, Alberti explica que a localização do ponto de fuga ("punctus centricus") - e, portanto, da linha do horizonte (linea centrica) - deve ser determinada a partir da altura aparente que o pintor decide atribuir ao homem de estatura média:

"Depois, dentro desse quadrângulo, fixo, onde me parece melhor, um ponto que ocupará o lugar que o raio cêntrico vai atingir e, por isso, eu o chamo de ponto cêntrico. Esse ponto está corretamente colocado quando não estiver mais alto da linha de base do quadrângulo que a altura de um homem que aí terá que ser por mim pintado, pois assim tanto quem vê quanto as coisas pintadas que se veem aparecem em um único e mesmo plano."288

Veremos que os pintores procedem de forma totalmente diferente: eles raramente situam a linha do horizonte à altura das cabeças dos personagens em pé e não procuram quase nunca sugerir que "os observadores e os objetos pintados que eles veem, apareçam em um único e mesmo plano”.

3. Ainda em I §19, logo antes do trecho que acaba de ser citado, Alberti impõe uma norma que, conquanto possa ser considerada arbitrária, desvela

287 Ibidem, De pict., I, § 18: "Haec eo spectant ut intelligamus in pictura quantulacunque pinxeris corpora, ea pro illic picti hominis commensuratione grandia aut pusilli videri. Hanc sane vim comparationis pulcherrime omnium antiquorum prospexisse Timanthes mihi videri solet, qui pictor, ut aiunt, Cyclopem dormientem parva in tabella pingens fecit iuxta satyros pollicem dormientis amplectentes ut ea satyrorum commensuratione dormiens multo maximus videretur.".

288 De pict., I, §19: "Post haec unicum punctum quo sit visum loco intra quadrangulum constituo, qui mihi punctus cum locum occupet ipsum ad quem radius centricus applicetur, idcirco centricus punctus dicatur. Condecens huius centrici puncti positio est non altius a iacenti linea quam sit illius pingendi hominis longitudo, nam hoc pato aequali in solo et spectantes et pictae res adesse videntur." Ibidem,, p.95. 
sua devoção pelas medidas provenientes do corpo humano. De fato, ele estipula que as dimensões dos paralelepípedos do pavimento pintado serão determinadas a partir da altura dos personagens: as laterais dos paralelepípedos devem corresponder a um terço da altura média do homem. Ora, a altura média do homem é, diz ele, de três "braços" (o braccio é uma unidade de medida que equivale a aproximadamente $58 \mathrm{~cm}$ ). Por conseguinte, independente da escala adotada, entende-se que os paralelepípedos deverão ter suas laterais medindo aproximadamente $58 \mathrm{~cm}$. Ademais, a borda inferior da imagem deve contar um número inteiro de paralelepípedos. Com efeito, Alberti parece excluir a possibilidade de frações de paralelepípedos aparecerem ao longo da borda inferior. Ao menos, é o que sugere a expressão adotada por ele para abordar a "divisão" da "linha de base mais baixa":

"Inicialmente, onde devo pintar, traço um quadrângulo de ângulos retos, do tamanho que me agrade, o qual reputo ser uma janela aberta por onde possa eu mirar o que aí será pintado, e aí determino de que tamanho me agrada que sejam os homens na pintura. Divido o comprimento desse homem em três partes, sendo para mim cada uma das partes proporcional à medida que se chama braço, porque, medindo-se um homem comum, vê-se que ele tem quase a medida de três braços, [efeito da "simetria" dos membros humanos]. E, de acordo com essa medida de braço, divido a linha da base do quadrângulo em tantas partes quantas deva ela comportar. Para mim, essa linha de base é proporcional àquela última quantidade com a qual me confrontei antes." 289

289 De pict., I, §19: "Principio in superficie pingenda quam amplum libeat quadrangulum rectangulorum angulorum inscribo, quod quidem mihi pro aperta finestra est ex qua historia contueatur, illicque quam magnos velim esse in pictura homines determino. Huiusque ipsius hominis longitudinem in tres partes divido, quae quidem mihi partes sunt proportionales cum ea mensura quam vulgus brachium nuncupat. Nam ea trium brachiorum, ut ex symmetria membrorum hominis patet, admodum communis humani corporis longitudo est. Ista ergo mensura iacentem infimam descripti quadranguli lineam in quot istiusmodi recipiat partes divido, ac mihi quidem haec ipsa iacens quadranguli linea est proximiori transversae et aequedistanti in pavimento visae quantitati proportionalis". Ibidem, p.94. 
Veremos que as normas preconizadas por Alberti absolutamente não encontram eco na prática dos pintores. Com efeito, os paralelepípedos dos pavimentos pintados são quase sempre menores do que prescreve Alberti: eles têm laterais medindo menos de um "braço". Ademais, os pintores inserem frequentemente fileiras fracionárias de paralelepípedos ao longo da borda inferior da imagem.

4. Em II §33, a largura e a profundidade das edificações pintadas são igualmente determinadas em função da estatura do homem, ao menos indiretamente. Com efeito, Alberti avalia esse comprimento e essa largura de acordo com o número de paralelepípedos do pavimento. Eles são, portanto, medidos em "braços". Logo, eles são indiretamente determinados pela altura do homem:

"Primeiro começo com os fundamentos. Coloco a largura e o comprimento das paredes em seus paralelos; nesse traçado sigo a natureza. [...] Começo sempre com as superfícies mais próximas, principalmente com aquelas que estejam igualmente distantes da intersecção. Coloco-as na frente das outras, descrevendo suas latitudes e longitudes naqueles paralelos do pavimento de tal modo que, quantos braços eu quiser ocupar, tantos paralelos apanho." 290

5. Enfim, sempre em II §33, algumas linhas após o trecho que acaba de ser citado, a altura - ou, se preferirmos, a elevação - das edificações pintadas é por sua vez, determinada partindo-se do comprimento dos personagens. De fato, ela é consequência lógica da altura do homem:

"Depois encontro a altura da parede por um sistema não muito difícil. Sei que a altura da parede contém em si esta proporção: a medida

290 De pict., I § 33: "Principio ab ipsis fundamentis exordium capio. Latitudinem enim et longitudinem murorum in pavimento describo [...] ac primo semper a proximioribus superficiebus incipio, maxime ab his quae aeque $a b$ intercisione distant. Itaque has ego ante alias conscribo, atque quam uelim esse harum ipsarum longitudinem ac latitudinem, ipsis in pauimento descriptis parallelis, constituo. Nam quot ea uelim esse brachia, tot mihi paralellos assumo." Ibidem, pp.112-113 
que ela tem do lugar onde começa no pavimento até a linha cêntrica, na mesma medida ela cresce para cima. Se se quer que essa quantidade do pavimento até a linha cêntrica seja da altura de um homem, haverá pois os três braços. Se se quer que a parede tenha 12 braços, eleva-se três vezes a distância da linha cêntrica até o lugar do pavimento."291

Ora, a prática dos pintores está longe de obedecer às prescrições de Alberti. Neste quesito, de fato, constata-se que a altura das edificações pintadas raramente pode ser avaliada em múltiplos inteiros da estatura média do homem. Outrossim, observa-se que, conquanto Alberti não cite personagens situados em diferentes níveis de elevação, acontece, em certas circunstâncias, dos pintores colocarem os mesmos em diferentes níveis de elevação da edificação (graças, particularmente, às escadas ou aos andares), enquanto que Alberti parece até mesmo excluir esta possibilidade já que, a seu ver, os personagens devem todos situar-se no mesmo plano do observador.

Às quatro etapas que acabamos de retraçar, vem acrescentar-se uma observação que afeta a unidade de medida a ser adotada. Alberti, como acabamos de ver, serve-se do "braço" a fim de determinar, a partir do corpo humano, as dimensões das edificações pintadas. Todavia, alguns parágrafos adiante, na reflexão voltada aos personagens, ele menciona uma segunda unidade de medida, igualmente derivada do corpo humano, a saber, o pé, mas só se refere a ela para depois rejeitá-la em proveito de uma terceira, também oriunda do corpo humano. Com efeito, ele preconiza empregar, para determinar as dimensões que convém dar às diferentes partes de um mesmo corpo, não o pé, como sugere Vitrúvio, mas a cabeça:

291 De pict., I § 33: "Tum altitudinem quoque superficierum hinc non difficillime assequor. Nam quae mensura est inter centricam lineam et eum pavimenti locum unde aedificii quantitas insurgit, eandem mensuram tota illa quantitas servabit. Quod si voles istanc quantitatem ab solo esse usque in sublime quater est hominis picti longitudo, et fuerit linea centrica ad hominis altitudinem posita, erunt tunc quidem ab infimo quantitatis capite usque ad centricam lineam bracha tria. Tu vero qui istanc quantitatem vis usque ad bracchia XII excrescere, ter tantumdem quantum est a centrica [linea] usque ad inferius quantitatis caput sursum versus educito.” Ibidem, pp.113 
"Uma coisa a se lembrar: para se medir bem um corpo animado deve-se apanhar um dos seus membros com o qual se medirão os outros. O arquiteto Vitrúvio media a altura dos homens pelos pés. Quanto a mim, parece-me coisa mais digna que os outros membros tenham referência com a cabeça, embora tenha notado ser praticamente comum em todos os homens que a medida do pé seja a mesma que vai do queixo ao cocuruto da cabeça."292

Alberti expõe abertamente a razão pela qual se opõe a Vitrúvio: se é melhor empregar como unidade de medida a cabeça ao invés do pé, isto se dá porque a cabeça ganha do pé em dignidade. Tal raciocínio - que poderíamos considerar como tipicamente humanista - é, sem dúvida, inconteste. Ainda assim, ele permanece totalmente alheio à prática artística da metade do século XV. Em primeiro lugar, porque na época os pintores não se interessavam verdadeiramente pelos cânones de proporção do corpo humano. Em seguida, - e sobretudo - porque é naturalmente pelos pés que os pintores fixam seus personagens aos paralelepípedos. O resultado é que, como veremos adiante, em pintura são os pés dos personagens e não sua cabeça (ou seus braços) que acabam servindo de unidade de medida. São os pés efetivamente que permitem aos pintores conferir aos pavimentos e às edificações que eles sustentam dimensões visíveis coerentes com aquelas dos personagens. Da mesma forma, são os pés - e não as cabeças ou os braços - que permitem aos observadores avaliar intuitivamente as dimensões dos paralelepípedos do pavimento e, por extensão, aquelas das edificações. Em outras palavras, o cuidado com a mensurabilidade, que se manifesta nos pintores e/ou nos mecenas mais inovadores da metade do século, pouco tem a ver com a dignidade do homem, supostamente concentrada, prioritariamente, em sua cabeça.

É praticamente impossível saber exatamente quais são as pinturas (ou baixos-relevos) que Alberti tem em mente, a título de modelos ou

292 De pict., I § 36: "Unum tamen admoneo, ut in commensurando animante, aliquod illius ipsius animantis membrum sumamus, quo caetera metiamur. Vitruvius architectus hominis longitudinem pedibus dinumerat. Ipse vero dignius arbitror si caetera ad quantitatem capitis referantur, tametsi hoc animadverti ferme commune esse in hominibus, ut eadem et pedis et quae est a mento ad cervicem capitis mensura intersit". Ibidem, pp. 116. 
contra modelos, quando redige o De pictura. A respeito desta vexata quaestio, sem dúvida estéril por si só, nos limitaremos a três observações, a primeira certa e as duas outras conjecturais. Em seguida passaremos a alguns estudos de caso.

Em primeiro lugar, as raras certezas das quais dispomos carecem de precisão. Na dedicatória em volgare a Brunelleschi, Alberti menciona quatro nomes de artistas modernos - o próprio Brunelleschi, Donatello, Ghiberti e Masaccio -, mas, com exceção da cúpula de Santa Maria del Fiore, ele não cita nenhuma obra específica destes quatro artistas. No corpo do tratado, a única obra não antiga evocada por ele, tanto em volgare como em latim, é a Navicella de Giotto. ${ }^{293}$

Ulteriormente, quando Alberti apregoa edificações pintadas podendo atingir altura três ou quatro vezes superior àquela dos personagens, pode-se conjecturar, sem muito medo de errar, que sua reflexão é, de modo geral, um contraponto à tradição - ainda bem viva na metade do século - das imagens de tipo mnemônico, nas quais a questão de uma escala comum às edificações e aos personagens, isto é, aos loci memoriae e aos imagines agentes que contém não se coloca. Em outras palavras, Alberti estaria constatando - ou encorajando - uma evolução cujas primeiras manifestações costumam situar-se por volta de 1425 . Todavia, nota-se que, mesmo em pintores reputados "modernos" como Masaccio, Fra Angelico ou Filippo Lippi, as edificações permanecem frequentemente exíguas, sobretudo em termos de altura, com relação às personagens que elas abrigam.

Pode-se pensar enfim que Alberti compartilha com os artistas e mecenas mais progressistas de seu tempo uma preocupação com a mensurabilidade das edificações pintadas que o conduz a rejeitar, sem dizê-lo abertamente, as perspetivas oblíquas, frequentes na tradição, em proveito exclusivo das perspetivas frontais, que facilitam a apreciação intuitiva das dimensões. ${ }^{294}$ Aqui também ele estaria acompanhando - ou

293 De pict., II $\$ 42$.

294 De pict., I 17. Cf. MAURICE BROCK, "La phobie du "tumulte" dans le De pictura", em Albertiana, VIII, 2005, pp. 119-180. 
favorecendo - uma evolução em curso: as edificações com perspetiva oblíqua (ou perspetiva angular) desaparecem progressivamente ao longo do século XV.

Desde que Alberti não nos tenha dado nenhuma informação precisa sobre as obras que tinha em mente ao redigir o De pictura, todo estudo de caso será necessariamente fruto de uma escolha arbitrária. Dos dois artistas florentinos abordados por nós, o primeiro pertence a uma geração anterior àquela do humanista, e o outro a uma geração posterior. O primeiro, Donatello (1386 ca.-1466), ao mesmo tempo em que apresenta uma vantagem - ele é nomeadamente designado na dedicatória em volgare do De pictura - oferece também um inconveniente. Trata-se, com efeito, de um escultor e não de um pintor. Ele se aproxima contudo da pintura pela sua abundante produção de baixos-relevos achatados, estilo conhecido como stiacciato. Dele analisaremos um baixo relevo bem conhecido cuja execução é, sem dúvida, contemporânea à primeira redação do De pictura. Quanto à reflexão a respeito do segundo artista, Benozzo Gozzoli (1422 ca.-97) - que exerce exclusivamente a pintura ela nos permite ter uma ideia, ainda que parcial, da preocupação com a mensurabilidade das edificações tal como ela se manifesta em um pintor florentino algumas décadas após o De pictura.

O baixo-relevo do Banquete de Herodes conservado em Lille (Palácio de Belas Artes, mármore, $50 \mathrm{~cm} \times 71 \mathrm{~cm}$ ) é não raro considerado como uma primeira aplicação do De pictura (daí sua data estimada em 1435). Na verdade, como o veremos, as prescrições do teórico só encontram ínfimo eco na obra do escultor.

Donatello põe em prática a "força da comparação". Ele o faz duplamente na metade direita do Banquete. Primeiro, ele justapõe um grupo de adultos em pé a uma criança sentada, assim como Alberti contrapôs um ciclope aos sátiros. Em seguida, este mesmo grupo de adultos permite aos observadores avaliar a altura das edificações. Com efeito, ele coloca, ao lado do grupo, uma escada. É suficiente, portanto, contar os degraus: as cabeças se situam ao nível do oitavo degrau, a escada contém ainda mais doze, a plataforma à qual ela conduz se situa portanto a uma altura igual a duas vezes e meia a altura média do homem. Notaremos contudo 
que Donatello lança mão aqui de um elemento nunca mencionado por Alberti: a escada para a qual os pintores costumam apelar.

Graças aos numerosos elementos arquitetônicos, é fácil determinar a localização da linha do horizonte (ela se situa ao nível da cabeça de Herodes, sentado na ponta da mesa do banquete) e do ponto de fuga (ele se encontra acima da cabeça da mulher vista de costas, sentada em um banco, no primeiro plano). Donatello coloca de fato, como o deseja Alberti, a "linha cêntrica" ao nível das cabeças dos personagens em pé, mas, contrariamente à sua prescrição, ao invés de " colocar o "ponto cêntrico" no centro geométrico da imagem, ele o desloca fortemente em direção à esquerda. Ademais, ele não respeita a prescrição de Alberti segundo a qual "os observadores e os objetos que eles vêm" devem estar "em um mesmo plano horizontal". De fato, o homem que põe o pé no segundo degrau da escada e se apoia na rampa não se encontra no mesmo plano dos personagens que assistem à dança de Salomé ou daqueles que estão em volta da mesa do banquete. Outrossim, se examinarmos com atenção a imagem, descobriremos que outros personagens repousam em um plano mais elevado do que aquele sobre o qual se encontram os protagonistas: é bem verdade que não há ninguém na ampla plataforma à qual conduz à escada, mas, atrás de Herodes, um pórtico abriga algumas figurilhas quase invisíveis (vemos apenas suas cabeças, tratadas em muito baixo relevo). Ora, tem-se acesso ao pórtico após subir três ou quatro degraus. Por conseguinte, as figurilhas encontram-se sobre um plano mais elevado do que aquele dos protagonistas.

Os paralelepípedos do pavimento praticamente se enquadram às prescrições de Alberti. Não é fácil distingui-los uns dos outros porque estão delimitados somente por finas incisões no mármore, mas parecem ter suas laterais medindo efetivamente perto de um "braço". Podemos ter intuitivamente uma ideia de sua medida se nos basearmos sobre o homem seminu, em pé, ao lado da escada que segura uma espada em sua mão direita. Com efeito, é suficiente comparar o comprimento do braço esquerdo, quase esticado, deste homem - sem dúvida o carrasco que acaba de decapitar São João-Bastista - à largura do paralelepípedo no ângulo do qual repousa a ponta de seu pé direito: o comprimento 
do braço parece sensivelmente idêntico à largura do paralelepípedo. A bem dizer, é muito mais cômodo servir-se do pé direito do carrasco - ou daquele de seu vizinho - para avaliar as dimensões dos paralelepípedos. Estes dois pés, diferentemente dos braços, estão, de fato, em contato direto com o pavimento. Se aumentarmos um pouco o comprimento destes dois pés a fim de compensar o ligeiro encurtamento que os acomete, constataremos que os paralelepípedos sobre os quais eles repousam têm uma largura de dois pés e, por conseguinte, de aproximadamente um "braço". Além disso, a fileira acompanhando a "linha de base mais baixa" é constituída de paralelepípedos inteiros e não de suas frações. Donatello respeita portanto escrupulosamente as prescrições de Alberti - com a única diferença de que são essencialmente os pés dos personagens, mais que seus braços, que permitem ao observador confirmar que os paralelepípedos têm efetivamente laterais medindo um "braço".

É impossível avaliar aqui em número de "braços" a largura e a profundidade das edificações. Ao menos, é impossível fazê-lo a olho nu. De fato, os personagens encobrem quase que inteiramente a implantação das edificações sobre o pavimento. Consequentemente, somente uma restituição gráfica fazendo abstração dos personagens permitiria medir a largura e a profundidade destas edificações. Em contrapartida, é possível - e fácil até - medir intuitivamente sua elevação. A ampla plataforma dominando a cena situa-se, com efeito, já o vimos, a uma altura equivalente a duas vezes e meia a altura média do homem. A avaliação desta altura passa, contudo, já o dissemos, por um recurso alternativo que Alberti absolutamente não previu: é necessária a presença de uma escada da qual possamos contar os degraus. Começa a ficar claro que, conquanto Alberti tenha desenvolvido um procedimento abstrato, intelectual, que o conduziu logicamente a privilegiar o braço e depois a cabeça, os artistas, por sua vez, exploraram os contatos concretos, físicos, entre corpos e suportes que os conduziram, de forma igualmente coerente, a servir-se de pés em contato com o solo ou subindo (virtualmente) escadas.

Benozzo Gozzoli ainda não foi apreciado à altura de suas qualidades como realisador de grandes afrescos. A fim de sermos breves, examina- 
remos uma única cena das Histórias de Santo Agostinho que ele pinta a fresco, de 1463 a 1466, sobre as paredes do coro da igreja de S. Agostinho em San Gimignano.

Na cena representando Santo Agostinbo na escola de Tagaste - que ocupa a metade da esquerda da parte inferior do muro esquerdo - não há dúvida de que os acidentes se dão a conhecer por comparação com o homem. Ao tratar uma cena de escola (os pais de Santo Agostinho o põem sob a guarda de um preceptor), Benozzo Gozzoli põe lado a lado adultos e crianças cuja altura é proporcional à sua idade. Ele se vale integralmente da "força da comparação", particularmente na parte inferior da imagem: sobre um pavimento bipartite, monocromático ao centro, tricromático à esquerda e à direita, pés de adultos avizinham-se aos pés de crianças e adolescentes.

A linha do horizonte situa-se ao nível das cabeças dos dois alunos mais velhos - e consequentemente mais altos - que ocupam o eixo vertical mediano da imagem e o ponto de fuga está localizado no cume da cabeça do primeiro destes dois alunos (daquele que tem uma cabeleira loira e cacheada). A localização do ponto de fuga está, de certa forma, conforme às prescrições de Alberti: ela coincide com o centro geométrico da imagem. Em contrapartida, a localização da linha do horizonte levanta uma dificuldade que o teórico não leva em conta. Com efeito, quando os personagens que estão em pé não têm todos a mesma altura, é impossível dar "ao ponto cêntrico" e à "linha cêntrica" uma "posição que convenha", isto é, segundo os termos de Alberti, uma posição "que não se eleve acima da linha de base mais do que a altura do homem a ser pintado". Qualquer que seja a localização escolhida pelo pintor, a linha do horizonte ou é muito alta (para as crianças, caso ela esteja ao nível das cabeças dos adultos), ou muito baixa (no caso dos adultos, se ela está ao nível das cabeças das crianças). Afora esta dificuldade - claramente resultante do caráter muito geral do discurso albertiano - podemos presumir que o pintor, ao tratar de uma cena de escola, adota deliberadamente o ponto de vista da criança: ele coloca o ponto de fuga sobre a cabeça de um adolescente que está a olhar uma pequena criança que se apresenta pela primeira vez à escola. 
O pavimento, ao mesmo tempo em que se enquadra às prescrições de Alberti, - na medida em que a primeira fileira é composta de paralelepípedos inteiros - os subverte no quesito das dimensões destes últimos. É de fato evidente, na região tricromática à direita, que os paralelepípedos são muito menores do que aconselha o teórico: eles têm laterais que medem, não um "braço", mas somente um pé, como o demonstram com insistência os seis pés - do adolescente, do adulto e da criança - que se sucedem a distâncias próximas. Para um prático como Benozzo Gozzoli, o homem é realmente a medida de todas as coisas, contudo, ele o é muito mais por seus pés do que por seus braços ou por sua cabeça.

Como acontece amiúde, as implantações das edificações no solo ficam quase que totalmente ocultas pelos personagens. Logo, é impossível medir intuitivamente a largura e a profundidade destas edificações. No entanto, é possível, ao menos à esquerda, medir sua altura, nem que seja aproximadamente. Com efeito, atrás do pai que confia o pequeno Agostinho ao preceptor, um comparsa adulto ladeia o pilar angular de um pórtico. A grande proximidade entre o comparsa e o pilar permite avaliar a altura do pórtico: podemos estimar que, do solo ao cume do arco, sua altura corresponde a uma vez e meia a altura média do homem adulto - o que faz dela, ao final, uma edificação modesta, sem grade amplitude, ainda próxima de um locus memoriae.

Não há dúvida de que seriam necessários mais estudos de casos. Estes viriam muito provavelmente confirmar que os pintores lançam mão invariavelmente do pé como unidade de medida dos pavimentos e que não raro avaliam a elevação das edificações tomando por base a estatura humana. Eles mostrariam igualmente que ocorre dos pintores implantarem fileiras fracionárias de paralelepípedos ao longo da borda inferior da imagem. Eles provam, se necessário, que o seu trabalho é em grande parte independente da teoria da Alberti. Por conseguinte, pode-se dizer que o De pictura oferece um testemunho da evolução da pintura, pode-se conceber talvez que ele acompanhe ou acelere esta evolução, mas não se pode absolutamente afirmar que ele fixe sua norma. 


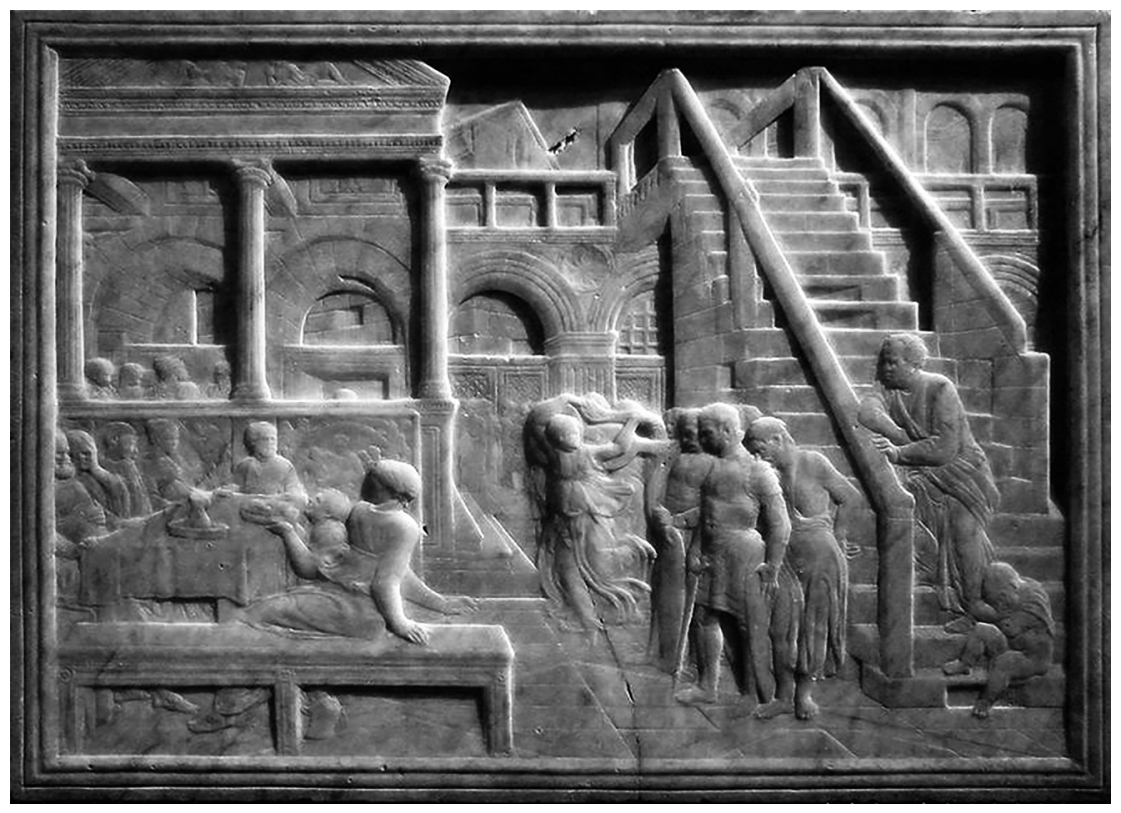

Fig. 1 - DONATEllo, Banquete de Hérodes, 1435 ca. Mármore, $50 \times 71$ $\mathrm{cm}$. Lille, Palais des Beaux-Arts.

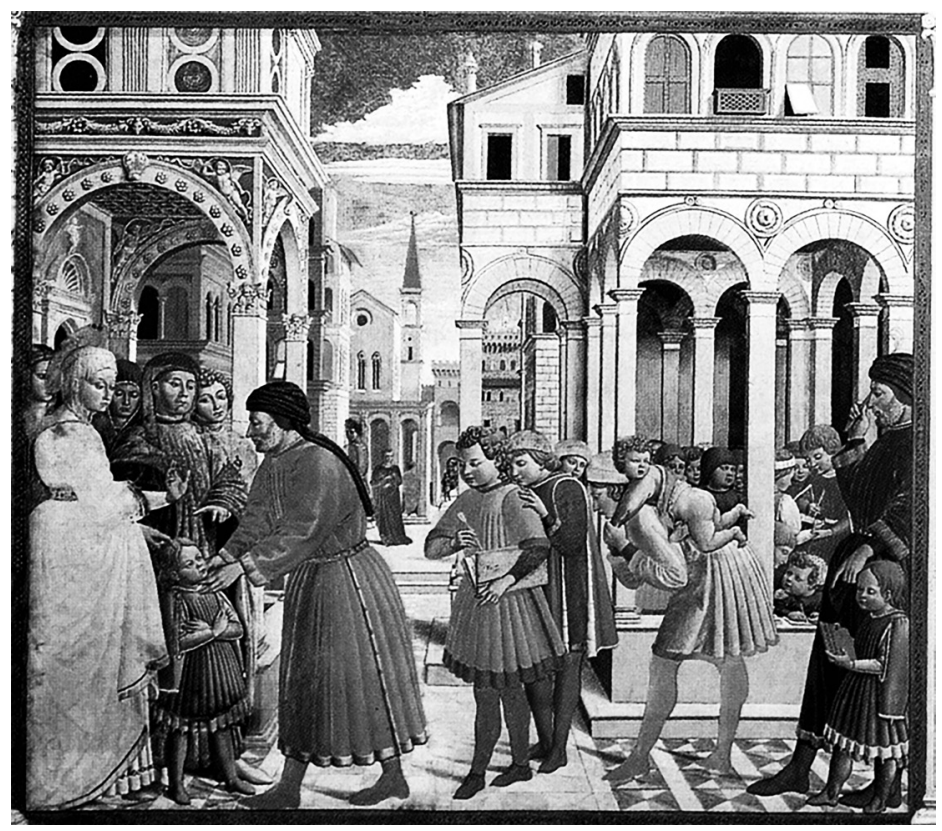

Fig. 2 - BENOZZO GOZZOLI, Santo Agostinho na Escola de Tagaste, 1463-66. Afresco. San Gimignano, Église S. Agostino. 